\title{
Restoration of plant communities on various dump substrates
}

\author{
Igor Gossen*, Sergey Solovyev \\ Institute of Soil Science and Agrochemistry SB RAS, Russia
}

\begin{abstract}
The results of field studies in 2018 and 2019 at the pilot production site on the territory of the external dump "Zarechny" of JSC SUEK-Kuzbass are presented. The ecological and coenotic characteristics of plant communities formed in the areas with the filling of the fertile soil layer (FSL) (0.5 m thickness), with the application of potentially fertile rocks (PFR) (1 m thickness), in the area with the filling of technogenic eluvium, as well as in the area with the layer-by-layer filling of PFR $(0.6 \mathrm{~m}$ thickness $)$ and FSL $(0.4 \mathrm{~m}$ thickness $)$ were studied. Geobotanical descriptions were carried out according to standard methods, taking into account iterations. It is established that in the first years after the end of the formation of the pilot production site, the number of herbaceous plant species increases in all areas. However, the use of lithogenic resources in the frame of reclamation accelerates the development of plant communities on man-made landscapes, but does not allow reaching the stages of zonal formations.
\end{abstract}

\section{Introduction}

The formation of vegetation cover on man-made landscapes, under favorable conditions, almost begins in the year of the end of the dump filling. First of all, weed species (pioneers) settle [1]. But not always even these unpretentious weeds can take root. For example, on dumps made of coarse-grained rocks, natural overgrowth is very slow or does not occur at all. However, as shown by researchers $[2,3]$, the use of such lithogenic resources as the fertile soil layer (FSL) or potentially fertile rocks (PFR) can significantly improve the physical and chemical properties of the habitat, which contributes to the development of successional processes. The projective coverage of the plots also differs and depends on the species composition of the plants and the soil substrate. The purpose of this work is to identify the features of the initial stages of the formation of vegetation cover on different substrates.

\section{Materials and Methods}

The research was carried out in the forest-steppe zone of the Kemerovo region on the

* Corresponding author: igor-gossen@yandex.ru 
territory of the external dump "Zarechny" of JSC SUEK-Kuzbass. In order to identify the features of the initial stages of the formation of vegetation cover on the dump, experimental sites were formed through different combinations of FSL and PFR: option I - application of FSL with a thickness of $0.5 \mathrm{~m}$; option II - control, material of the dump; option III application of PFR with a thickness of $1 \mathrm{~m}$; option IV - layer-by-layer application of PFR with a thickness of $0.6 \mathrm{~m}$ and FSL with a thickness of $0.4 \mathrm{~m}$. [4]. At each site, a series of geobotanical descriptions were carried out (accounting plots with an area of $100 \mathrm{~m} 2$ ) and, the gathering of aboveground phytomass (mowing) was carried out in three iterations on plots with an area of $1 \mathrm{~m}^{2}[5]$.

\section{Results}

Observing the dynamics of vegetation cover restoration at the studied sites in 2019 compared to 2018, the following was noted. On the sites, seedlings of tree species were planted - Pinus sylvestris L., Acer negundo L., Sorbus aucuparia L. and Betula pendula Roth, the condition and number of which, during the period of observation, did not change. The increase was on average about $10-15 \mathrm{~cm}$, the vitality according to Brown-Blanquet and Babillard (1922) [5] "satisfactory" - the species is vegetatively developed well, but only some plants bear fruit.

On a first site with a $0.5 \mathrm{~m}$ FSL filling, the changes in the community structure are not noticeable. The herbage is dominated by cereals and legumes. The projective coverage remained at the same level of $80 \%$ with the predominant species - Phlum pratense L., Trifolium pratense L., however, Hypericum perforatum L. was added to the dominant species compared to 2018. The number of species on this site is also characterized by a slight increase from 16 to 22, while two single species - Calamagrostis epigeios (L.) Roth and Ranunculus acris L. - disappeared from the community. The appearance of meadow species is associated with the preserved seed bank in the applied FSL. The aboveground production of herbaceous plants during the observation period varies from 2801 to 308 hundredweight per hectare. At the same time, as shown in Table 1, there is an increase in the biomass of cereal species by almost two times, and a decrease in the productivity of grass species by two times. The soil is humus-rich technozem.

Changes in the herbaceous layer on the site No. 2, the soil cover of which is represented by overburden and host rocks, are more noticeable. In particular, on most of the accounting plots, there was a change in the dominant species. Thus, in 2018, Cirsium setosum (Willd.) Besser, Melilotus officinalis (L.) Pall and Conyza canadensis (L.) Cronquist predominated in the area filled with technogenic eluvium with a projective coverage of $30 \%$, in 2019 there was some change. The number of species doubled from 9 to 18; at the same time one specie, M. officinalis, "dropped out" of the community. In addition, the site was divided into two parts with different projective coverage. The first part is characterized by a decrease in the projective coverage to $10 \%$, with the predominance of $C$. setosum, $C$. vulgare (Savi) Ten., Tripleurospermum inodorum (L.) Sch. Bip. and Tussilago farfara L. The soil cover is represented by the initial embryozem. These stages of soil formation are characterized by annual species that quickly populate new free ecotopes and also quickly drop out of the cenosis. They can't compete with perennials. At the second part, in comparison with last year, the projection coverage remained the same, however, the number of $C$. vulgare significantly increased. The soil cover is represented by an organoaccumulative embryozem, on which weedy plant groups are formed. This separation is due to the granulometric composition of the substrate and, as a result, the degree of moisture and, consequently, the availability of mineral substances for plants. As shown in Table 1, there are no cereals and legumes species of herbaceous plants on the site, the aboveground phytomass is from 40 to 106 hundredweight per hectare. 
Significant changes are observed in the community growing on lithogenic technozem (1 $\mathrm{m}$ thickness PFR fill) (site No. 3). The projective coverage increased from $50 \%$ to $95 \%$, the species diversity also increased from 22 to 26 species, with 6 species noted in 2018, but not recorded in the 2019 study. Changes are also observed in the composition of the dominant species, replacing C. canadensis and T. farfara with Medicago falcata L. and C. vulgare, the latter being very abundant. The aboveground phytomass of plants varies from 921 to 1056 hundredweight per hectare (Table 1).

The projective coverage of plants on humus-rich technozem with a layer-by-layer filling of FSL $0.4 \mathrm{~m}$ + PFR $0.6 \mathrm{~m}$ (site No. 4), as well as on the previous site, changed from 50 to $95 \%$. However, the species diversity decreased from 32 to 28 species. At the same time, 11 species disappeared from the communities. In the composition of the dominant species, castling occurred: C. canadensis, which dominated in 2018, was replaced by C. vulgare; the same pattern is observed in the co-dominants: in addition to T. farfara, such species as $\mathrm{M}$. falcata, C. setosum and T. inodorum appeared. Besides, Linaria acutiloba Fisch. ex Rchb and Agrostis tenuis Sibth. was added to the co-dominants. The conducted mowing showed the yield of aboveground phytomass around 721-732 hundredweight per hectare (Table).

Table. Biomass of herbaceous plants.

\begin{tabular}{|c|c|c|c|c|}
\hline \multirow{2}{*}{ Year } & \multicolumn{3}{|c|}{ Plant type } & \multirow{2}{*}{ Yield, h/ha } \\
\hline & cereal & legume & grass & \\
\hline \multicolumn{5}{|c|}{ Site 1, FSL filling } \\
\hline 2018 & 108 & 124 & 48 & 280 \\
\hline 2019 & 192 & 96 & 20 & 308 \\
\hline \multicolumn{5}{|c|}{ Site 2, technogenic eluvium filling } \\
\hline 2018 & - & - & 40 & 40 \\
\hline 2019 & - & - & 106 & 106 \\
\hline \multicolumn{5}{|c|}{ Site 3 , PFR filling } \\
\hline 2018 & 74 & 254 & 593 & 921 \\
\hline 2019 & 67 & 248 & 741 & 1056 \\
\hline \multicolumn{5}{|c|}{ Site 4, PFR+FSL layer-by-layer filling } \\
\hline 2018 & 176 & 85 & 460 & 721 \\
\hline 2019 & 211 & 136 & 385 & 732 \\
\hline
\end{tabular}

\section{Discussion}

The conducted studies show that the filling of FSL (site 1) allows you to quickly form a herbaceous vegetation cover; biodiversity is quickly restored with natural overgrowth, which indicates a high number of seeds in the substrate. At the initial stages, even rare redbook species appear which are subsequently replaced by the predominant weed and meadow species of herbaceous plants. The projective coverage is $80 \%$, and the number of growing species is also increasing. The applied humus layer helps to improve the quantitative and qualitative characteristics of the vegetation cover.

No continuous vegetation cover was formed on the site without the use of lithogenic resources of reclamation during the research work. The projective coverage is from 10 to 40 $\%$. The site is dominated by pioneer and weed species, which indicates the unfavorable physical and chemical properties of the substrate.

At $t$ the site with PFR (loam) filling at the initial stages of the development of phytocenoses, pioneer (undemanding to the quality of substrates) species predominate in 
the herbage. Subsequently, they are replaced by the weedy stage of phytocenosis development, and legume species appear. The projective coverage increases from $50 \%$ to $95 \%$, and the number of growing herbaceous plant species also increases. This indicates more favorable soil conditions for the growth and development of plants.

Site 4 is formed according to the classic technology with layer-by-layer filling of PFR and FSL. This method of recultivated surface creating simulates the structure of natural soils. The fertility and stability of soil-like formations (technozem) depends on the quantity and quality of the materials used. The formation of technozems using this technology allows you to create vegetation cover of various types and directions. In our case, peat was used in the formation. Weeds predominate on sites with natural restoration of plant communities, although there are also plants characteristic to swamp ecosystems. In the future, plant species from waterlogged habitats "drop out" of the phytocenosis during 3-4 years of growth. Thus, the number of selected species decreases from 32 to 28 , while the projective coverage on the site increases from 50 to $95 \%$. At the site, there are territories with a predominance of cereals and legumes, as well as areas with the growth of various grass species.

The study was carried out according to the state assignment of ISSA SB RAS. The Russian Foundation for Basic Research № 19-29-05086.

\section{References}

1. O.I. Glebova, Nature and economic of Kuzbass, 2, 4-9 (2004)

2. I.S. Semina, Occupational Safety in Industry,11, 36-38 (2013)

3. D.A. Sokolov, O.E. Merzlyakov, E.A. Domozhakova, Tomsk State University Journal, 399, 247-253. (2015)

4. V.A. Androkhanov, A.T. Lavrinenko, I.N. Gossen, E.D. Kulyapina, Russian Coal Journal, 12, 60-65 (2019)

5. A.G. Voronov, Geobotany (Moscow: Higher school Publ., 1973) 